\title{
Characteristics of Resistant Lines to High-Temperature Injury in Gin- seng (Panax ginseng C. A. Meyer)
}

\author{
Joon-Soo Lee*, Jang-Ho Lee, and In-Ok Ahn \\ Natural Resources Research Institute, R\&D Headquarters, Korea Ginseng Corporation, Daejeon 305-345, Korea
}

This experiment was conducted to examine ginseng lines resistant and susceptible to high-temperature injury and to investigate characteristics of the selected lines: leaf burning phenomenon, chlorophyll content, quantum yield, and maximum light interception rate. The leaf burning phenomenon incidence rates of the resistant lines Yunpoong, high-temperature injury resistance (HTIR)1, HTIR2, and HTIR3 were low: 5.8\%, 3.6\%, 4.0\%, and 1.9\%, respectively. Resistance of the susceptible lines Chunpoong, high-temperature injury susceptible (HTIS)1, and HTIS2 was high: 58.5\%, 23.2\%, and 21.7\%, respectively. The chlorophyll content (SPAD value) of the resistant lines Yunpoong, HTIR1, HTIR2, and HTIR3, which were exposed to high temperatures and intense light, remained as high at 24.8, 27.9, 24.9, and 30.6, respectively, but that of the susceptible lines Chunpoong, HTIS1, and HTIS2 was low at 21.0, 21.1, and 20.1, respectively. During the summer season, the quantum yield of the resistant lines (Yunpoong, HTIR1, HTIR2, and HTIR3) changed little, but that of the susceptible lines (Chunpoong, HTIS1, and HTIS2) changed dramatically. The maximum light interception rate (Fm/Fv value) for the resistant lines (Yunpoong, HTIR1, HTIR2, and HTIR3) was as high as $0.848,0.794,0.805$, and 0.813 , respectively, while that of the susceptible lines (Chunpoong, HTIS1, and HTIS2) was $0.678,0.642$, and 0.717 , respectively. Based on these results, the hightemperature injury-resistant lines seemed to be less susceptible to high light, even at high temperatures. Future studies on red ginseng quality and its active ingredients in resistant ginseng lines and field experimentation will be conducted to verify the potential of the resistant lines.

Keywords: High-temperature injury, Leaf burning, Quantum yield, Fm/Fv, Resistant line

\section{INTRODUCTION}

Ginseng (Panax ginseng C. A. Meyer) is a deciduous perennial semi-shade plant that is very vulnerable to high temperatures and intense light, and thus should be shaded from direct sunlight during field growth. Optimum temperature and light intensity are $21^{\circ} \mathrm{C}$ to $25^{\circ} \mathrm{C}$ and 10,000 lux to 15,000 lux, respectively, for good ginseng growth. leaf burning phenomenon (burning of leaf margins) is found on ginseng plants that grow in shade where the canopy temperature remains above $30^{\circ} \mathrm{C}$ for 1 week, leading to later whole-leaf burning or bleaching due to the destruction of pigments in leaf tissues. Leaf burning leads to inhibition of the photosynthetic dark reaction and photoinhibition in leaves damaged by high temperatures and intense light, which are deprived of electron acceptors for transfer to oxygen molecules, and in the Mehler reaction, free radicals of oxygen $\left(\mathrm{O}_{2}^{-},{ }^{1} \mathrm{O}_{2}\right.$, and $\mathrm{H}_{2} \mathrm{O}_{2}$ ) cause oxidative damage to leaves [1,2].

Leaf burning of ginseng during growing seasons is highest in 1-year-old to 3-year-old seedling stages, but is less in 4-year-old ginseng. Root weights are reduced (as (c) This is an Open Access article distributed under the terms of the Creative Commons Attribution Non-Commercial License (http://creativecommons.org/licenses/by-nc/3.0/) which permits unrestricted non-commercial use, distribution, and reproduction in any medium, provided the original work is properly cited.
Received 15 Apr. 2010, Revised 9 Jul. 2010, Accepted 15 Jul. 2010

"Corresponding author

E-mail: cbmleejs@kgc.or.kr

Tel: +82-42-870-3133, Fax: +82-42-870-3117 
is root specific gravity) by leaf burning to $50.0 \%(67.8 \%)$ in 1-year-old seedlings and to $48.9 \%(19.0 \%), 24.6 \%$ (4.7\%), $11.5 \%$ (3.5\%), and $10.5 \%(8.5 \%)$ in $2-, 3-, 4-$, and 6-year-old plants, respectively. This results in a decrease in red ginseng quality of 6-year-old roots, which become more spongy in texture, with an internal cavity and white color [3].

Leaf burning phenomenon can be reduced through several cultural practices, including transplanting seedlings with longer roots ( $35 \%$ for $8 \mathrm{~cm}$ vs. $12 \%$ for $\geq 10$ $\mathrm{cm}$ ), irrigation (35\% without irrigation vs. $6 \%$ with irrigation), and installation of thicker shade material (64\% for four layers of polyethylene [PE] net vs. 20.3\% for four layers of PE plus two of black PE net) [4]. However, continuous temperature increases in Korea, influenced by the current global warming, make these cultural practices alone less effective in preventing ginseng leaf burning. Lee et al. [5] studied ginseng lines resistant to leaf burning and found five resistant lines, with leaf burning phenomenon of $32 \%$ to $44 \%$ compared to the susceptible violet-stem variant (Jakyungjong) with a leaf burning of $62 \%$. Later, six ginseng lines with leaf burning of less than $1.9 \%$ were selected. Other studies include examination of leaf burning phenomenon in relation to ginseng age and development of the leaf cuticle in the lines Chunpoong and Yunpoong [6,7], and characterization of aboveground and belowground traits of five lines resistant to leaf burning [8]. However, seasonal leaf burning phenomenon in selected ginseng lines and photoinhibition in ginseng leaves exposed to high temperatures and light intensities have not been fully documented.

This study was conducted to examine seasonal leaf burning phenomenon and characteristics of aboveground and belowground parts of selected ginseng lines susceptible or resistant to leaf burning. Also, photoinhibition in the selected ginseng lines exposed to high temperatures and light intensities was examined in terms of changes in chlorophyll content, quantum yield, and maximum light interception $(\mathrm{Fm} / \mathrm{Fv})$, with the aim of providing basic information for selecting ginseng lines resistant to leaf burning.

\section{MATERIALS AND METHODS}

This study was conducted in 2008 in the Bioresource Research Center of KT\&G Central Research Institute at Suwon, Gyeonggi province, Korea. The ginseng plants used in this study were four leaf burning-resistant lines (Yunpoong, high-temperature injury resistance [HTIR]1, HTIR2, and HTIR3), three susceptible lines (Chunpoong, high-temperature injury susceptible [HTIS]1, and HTIS2) and eight lines of the native violet-stem variant (Jakyungjong) (Table 1). Ginseng rooted seedlings were transplanted into ginseng beds of $1.62 \mathrm{~m}^{2}$ in area, with 54 seedlings ( 6 plants $\times 9$ rows) in a bed and three replications in a randomized block design. The ginseng plants were grown under $20 \%$ shading from transplanting time (late April) until root harvest (late October) for the artificial induction of leaf burning. Additional two layers of black shading were not used, and front, rear, and side shading was not applied. No artificial irrigation was given even during the high-temperature period. Other cultural practices followed the standard ginseng cultivation method. Temperature changes in canopies under the shading were recorded $24 \mathrm{~h}$ a day from late April

Table 1. Characteristics of seedlings in ginseng lines resistant and susceptible to high temperature injury

\begin{tabular}{|c|c|c|c|c|c|c|}
\hline \multirow{3}{*}{ Reaction } & \multirow{3}{*}{ Lines } & \multicolumn{5}{|c|}{ Seedling } \\
\hline & & \multirow{2}{*}{$\begin{array}{c}\text { Distribution of } \\
\text { anthocyanin at stem }^{1)}\end{array}$} & \multirow{2}{*}{ Fruit color } & \multicolumn{3}{|c|}{ Root } \\
\hline & & & & Weight (g) & Length $(\mathrm{cm})$ & Diameter $(\mathrm{mm})$ \\
\hline \multirow{4}{*}{ Resistant } & Yunpoong & 1 & Red & $0.71 \pm 0.3^{2)}$ & $16.0 \pm 0.8$ & $5.0 \pm 0.3$ \\
\hline & HTIR1 & 2 & Red & $0.75 \pm 1.1$ & $15.5 \pm 0.9$ & $5.0 \pm 0.2$ \\
\hline & HTIR2 & 2 & Red & $0.76 \pm 1.3$ & $17.0 \pm 1.8$ & $5.1 \pm 0.5$ \\
\hline & HTIR3 & 2 & Red & $0.72 \pm 2.0$ & $16.1 \pm 1.8$ & $4.8 \pm 1.0$ \\
\hline \multirow{3}{*}{ Susceptible } & Chunpoong & 1 & Orange & $0.56 \pm 1.5$ & $14.8 \pm 1.9$ & $5.0 \pm 1.2$ \\
\hline & HTIS1 & 1 & Red & $0.68 \pm 1.0$ & $14.8 \pm 1.5$ & $5.3 \pm 0.2$ \\
\hline & HTIS2 & 1 & Red & $0.48 \pm 0.8$ & $15.0 \pm 1.7$ & $4.3 \pm 0.1$ \\
\hline Control & Jakyungjong & 4 & Red & $0.60 \pm 0.9$ & $15.5 \pm 1.4$ & $5.2 \pm 0.3$ \\
\hline
\end{tabular}

HTIR, high temperature injury resistance; HTIS, high temperature injury susceptible.

1) 1 , on lower part only; 2 , on lower and upper part; 4 , along the whole stem.

${ }^{2)}$ Values are presented as mean \pm SE. 
through early September using an automatic temperature logger (Hobo; Onset Computer Corp., Pocasset, MA, USA) installed $15 \mathrm{~cm}$ above the bed's ridge surface.

\section{Phenomenon of leaf burning with time during cul- tivation}

Phenomenon of leaf burning were examined at 7-day intervals from 16 July 2008, when the first leaf burning occurred, until 3 September 2008. The occurrence of leaf burning was determined if more than one-third of leaf margins burned, and the phenomenon (P) (\%) of leaf burning was calculated as $(\mathrm{P}=$ number of leaves with burning phenomenon / total number of leaves in a plant $\times 100)$.

\section{Changes in chlorophyll content and photoinhibi- tion}

Chlorophyll content was measured with a chlorophyll meter (SPAD-502, Minolta, Osaka, Japan) three times at intervals of 1 month (25 June, 25 July, and 25 August 2008) on central leaflets of five ginseng plants grown in the third row of a bed. Quantum yield and the maximum light interception rate were examined to assess the degree of photoinhibition, at the same time as chlorophyll measurement on the same individual ginseng plant, as changes in chlorophyll fluorescence using a pulse amplitude modulation fluorometer (PAM-2000; Walz, Effeltrich, Germany).

\section{Aboveground and belowground growth}

For each treatment, leaf area and specific leaf weight were examined for five plants with three replications after 16 June 2008, when the aboveground parts were fully foliated, using a Li-3000C portable area meter (Li-COR, Lincoln, NE, USA). Root length, diameter, and weight were examined for 10 roots with three replications on 20 October 2008, when the roots were harvested.

\section{RESULTS AND DISCUSSION}

\section{Phenomenon of leaf burning with time during cul- tivation}

The first leaf burning phenomenon, with an incidence of $0.5 \%$, occurred in Jakyungjong and HTIS1 on 16 July 2008 , when canopy temperatures of over $30^{\circ} \mathrm{C}$ persisted for 28 days. This leaf burning occurrence is similar to that reported in a previous study on leaf burning development with 30 accumulated days of temperatures over $30^{\circ} \mathrm{C}$ [3]. The leaf burning incidences on 23 and 30 July 2008 were $1.5 \%$ and $2.7 \%$, respectively, in Jaky- ungjong, while burning in other lines was absent or less than $0.6 \%$. Thereafter, the leaf burning phenomenon increased continuously to $14.4 \%$ on 3 September 2008 in Jakyungjong, confirming that this ginseng variant is susceptible to leaf burning. In Chunpoong, the leaf burning phenomenon was $1.5 \%$ on 6 August and rapidly increased to $19.6 \%$ on 13 August; thereafter, it increased continuously to a final value of $58.5 \%$ on the last examination date, 3 September, confirming that this ginseng line is the most susceptible to leaf burning. Leaf burning phenomenon was 5.3\% in HTIS1 and 5.2\% in HTIS2 on 27 August, with a rapid increase thereafter to $23.2 \%$ and $21.7 \%$, respectively, on 3 September, confirming that these two lines are also susceptible to leaf burning. No leaf burning phenomenon were found in Yunpoong (resistant), HTR1, HTIR2, and HTIR2 on 16 July, when Jakyungjong showed its first leaf burning phenomenon; an incidence of only $0.1 \%$ was observed in HTIR 2 on 23 July, with none in the other resistant lines. On $13 \mathrm{Au}-$ gust, when the susceptible Chunpoong had a leaf burning phenomenon of $19.6 \%$, the incidences were still low at $2.2 \%, 0.7 \%, 0.6 \%$, and $0.6 \%$ for Yunpoong, HTIR1, HTIR2, and HTIR2, respectively. The phenomenon of leaf burning at the final examination (3 September) in the above ginseng lines were very low compared to those in Chunpoong, with phenomenon of 5.8\%, 3.6\%, $4.0 \%$, and $1.9 \%$ for Yunpoong, HTIR1, HTIR2, and HTIR2, respectively, confirming that they are all resistant to leaf burning (Table 2).

The reported phenomenon of leaf burning in 2-yearold ginseng plants of the resistant lines were $9.1 \%$ in Yunpoong, 5.1\% in HTIR1, 6.8\% in HTIR2, and 1.9\% in HTIR3 [6], which is congruent with our study, confirming that these resistant lines had low leaf burning phenomenon. Another report found the susceptible line Chunpoong had a leaf burning phenomenon of 53.6\% [7], which also coincides with our results (leaf burning phenomenon of 58.3\%). Incidences of leaf burning were very high in HTIS1 (77.8\%) and HTIS2 (86.7\%) [8] compared to the results of our study, probably because that study used ginseng seedlings while we used 2-year-old ginseng plants. Lee et al. [7] reported that the development of the cuticle in leaves was more distinct in Yunpoong than in Chunpoong, suggesting that a thick cuticle reduces light interception but not transpiration through the leaf surface, thus inhibiting the increase of leaf temperature, and that leaf burning is more common in leaves with a thin and less developed cuticle. The development of the cuticle in relation to leaf burning resistance will be studied in future experiments. 
Table 2. Changes of leaf burning phenomenon in 2-year-old ginseng lines resistant and susceptible to high temperature injury during the summer season

\begin{tabular}{|c|c|c|c|c|c|c|c|c|c|}
\hline \multirow[b]{2}{*}{ Reaction } & \multirow[b]{2}{*}{ Line } & \multicolumn{8}{|c|}{ Examination day } \\
\hline & & $\begin{array}{c}16 \\
\text { Ju1 } \\
(28)^{1)}\end{array}$ & $\begin{array}{c}23 \\
\text { Ju1 } \\
(36)\end{array}$ & $\begin{array}{c}30 \\
\text { Ju1 } \\
(40)\end{array}$ & $\begin{array}{c}06 \\
\text { Aug } \\
(47)\end{array}$ & $\begin{array}{c}13 \\
\text { Aug } \\
(54)\end{array}$ & $\begin{array}{c}20 \\
\text { Aug } \\
(58)\end{array}$ & $\begin{array}{c}27 \\
\text { Aug } \\
(63)\end{array}$ & $\begin{array}{c}03 \\
\text { Sep } \\
(67)\end{array}$ \\
\hline \multirow{4}{*}{ Resistant } & Yunpoong & $-^{2)}$ & - & 0.3 & 1.7 & 2.2 & 2.7 & 3.3 & 5.8 \\
\hline & HTIR1 & - & - & 0.2 & 0.6 & 0.7 & 0.9 & 1.6 & 3.6 \\
\hline & HTIR2 & - & 0.1 & 0.1 & 0.3 & 0.6 & 0.9 & 1.3 & 4.0 \\
\hline & HTIR3 & - & - & - & 0.2 & 0.6 & 0.6 & 1.1 & 1.9 \\
\hline \multirow{3}{*}{ Susceptible } & Chunpoong & - & - & 0.1 & 1.5 & 19.6 & 25.6 & 34.3 & 58.5 \\
\hline & HTIS1 & 0.5 & 0.5 & 0.6 & 0.6 & 1.0 & 2.2 & 5.3 & 23.2 \\
\hline & HTIS2 & - & - & - & 0.6 & 1.2 & 2.7 & 5.2 & 21.7 \\
\hline Control & Jakyungjong & 0.5 & 1.5 & 2.7 & 3.2 & 3.8 & 4.8 & 7.8 & 14.4 \\
\hline
\end{tabular}

Values are presented as percentage.

HTIR, high temperature injury resistance; HTIS, high temperature injury susceptible.

${ }^{1)}$ Accumulate day of over temperate of $30^{\circ} \mathrm{C}$ degree.

${ }^{2)}$ Non-infection.

The leaf burning phenomenon rapidly increased in both susceptible and resistant ginseng lines from 6 to 13 August 2008 in our study. The canopy temperature under the shading from 07:00 through 18:00 $\mathrm{h}$ remained above $30^{\circ} \mathrm{C}$ for $10 \mathrm{~h}$ and over $35^{\circ} \mathrm{C}$ for $4 \mathrm{~h}$, on average, while canopy temperature during the night, from 21:00 through to $06: 00 \mathrm{~h}$ the next day was never below $20^{\circ} \mathrm{C}$ (with a minimum of $23^{\circ} \mathrm{C}$ and a maximum of $25^{\circ} \mathrm{C}$ ). From 08:00 to 10:00 h, the canopy temperature rose rapidly to more than $30^{\circ} \mathrm{C}$, when morning sunlight reached under the shading; this persisted for 6 days, all except 12 August when $24 \mathrm{~mm}$ precipitation occurred. The average integrated sunshine was $0.4 \mathrm{~h}$ less, the average cloud cover was $10 \%$, and the average relative humidity was $92 \%$, according to weather data from the regional meteorological office [9]; hence, the average canopy temperature under shading was $27^{\circ} \mathrm{C}$ during the day and $24^{\circ} \mathrm{C}$ at night on this date, but was never below $20^{\circ} \mathrm{C}$ (Fig. 1).

The canopy temperature during this period was confirmed to be $3^{\circ} \mathrm{C}$ to $7^{\circ} \mathrm{C}$, higher than the optimum temperature range for ginseng growth of $21^{\circ} \mathrm{C}$ to $25^{\circ} \mathrm{C}$. Also, the plants growing at temperatures above $30^{\circ} \mathrm{C}$ from $08: 00$ for 1 week were assumed to have suffered critical damage due to decreased photosynthesis and increased respiration, as the optimum temperature for photosynthesis in ginseng is $15^{\circ} \mathrm{C}$ to $22^{\circ} \mathrm{C}$. The times when temperatures were over $35^{\circ} \mathrm{C}$ during the day and around $25^{\circ} \mathrm{C}$ at night for 1 week were a critical development stage for burning induction in ginseng. Susceptible ginseng lines suffer damaging photoinhibition at high temperatures and do not recover when the temperature decreases, while resistant lines can tolerate this photoinhibition, probably because they can dissipate heat. Therefore, the heat dis-

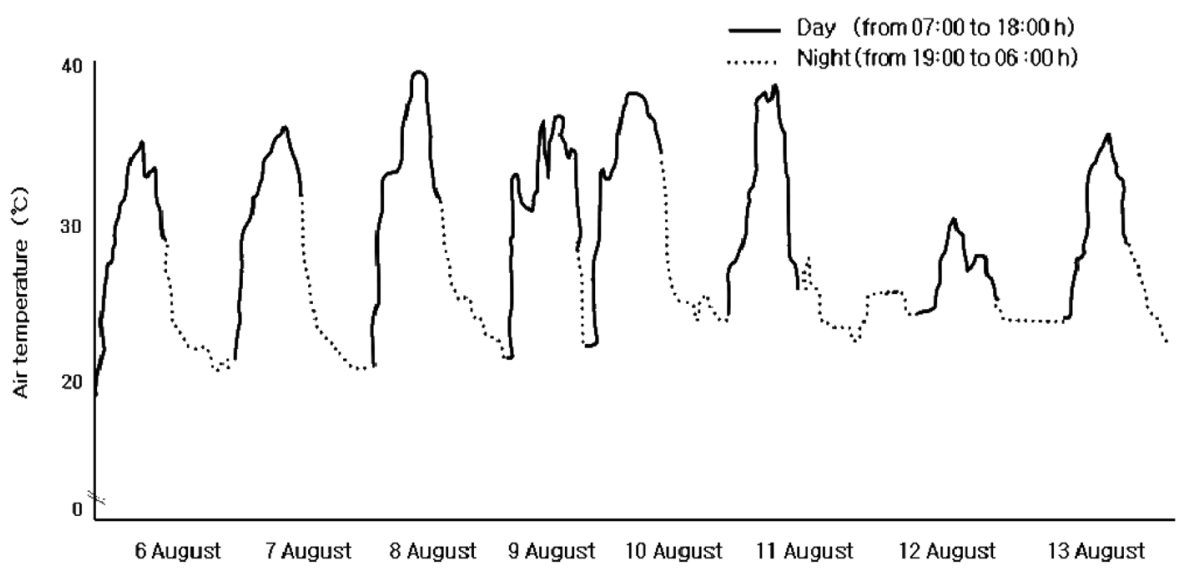

Fig. 1. Fluctuations of daily air temperature in the ginseng canopy under shading during the summer season. 
sipation characteristics of resistant ginseng lines should be extensively examined to develop lines resistant to leaf burning.

\section{Changes in chlorophyll content and photoinhibi- tion}

Changes in chlorophyll content (SPAD value) with time after planting are shown in Table 3. The respective chlorophyll contents of the resistant ginseng lines Yunpoong, HTIR1, HTIR2, and HTIR3 were 26.1, 30.1, 26.8, and 30.9 in June; 27.6, 35.7, 30.0, and 32.3 in July; and 24.8, 27.9, 24.9, and 30.6 in August; the values indicated little change in chlorophyll content during the hot summer, suggesting little chlorophyll destruction during hot temperatures and intense light in these resistant lines. In contrast, the susceptible lines Chunpoong, HTIS1, and HTIS2 had chlorophyll contents of 26.3, 26.1, and 28.0 in June; 25.9, 26.6, and 25.3 in July; and 21.0, 21.1, and 20.1 in August, respectively, indicating a steady decrease in chlorophyll with time during the hot summer. This suggests that pigments are destroyed by photooxidation during the hot season, leading to a decrease in chlorophyll content in leaves of the susceptible ginseng lines. However, the chlorophyll content in Jakyungjong (violet-stem variant) did not decrease very much (28.8 in June, 30.1 in July, and 26.3 in August) during this hot season, possibly because this variety is a mixture of various genetic resources. Yang et al. [2] reported that the chlorophyll and carotenoid contents decrease with increases in temperature. Lee et al. [10] also reported that chlorophyll content decreases rapidly as light trans-

Table 3. Changes of chlorophyll content (SPAD value) in 2-yearold ginseng lines resistant and susceptible to high temperature injury during the summer season

\begin{tabular}{ccccc}
\hline \multirow{2}{*}{ Reaction } & \multirow{2}{*}{ Lines } & \multicolumn{3}{c}{ Examination day } \\
\cline { 3 - 5 } & & $25 \mathrm{Jun}$ & $25 \mathrm{Jul}$ & $26 \mathrm{Aug}$ \\
\hline \multirow{4}{*}{ Resistant } & Yunpoong & $26.1^{\mathrm{cl})}$ & $27.6^{\mathrm{bc}}$ & $24.8^{\mathrm{bc}}$ \\
& HTIR1 & $30.1^{\mathrm{ab}}$ & $35.7^{\mathrm{a}}$ & $27.9^{\mathrm{ab}}$ \\
& HTIR2 & $26.8^{\mathrm{bc}}$ & $30.0^{\mathrm{bc}}$ & $24.9^{\mathrm{bc}}$ \\
& HTIR3 & $30.9^{\mathrm{a}}$ & $32.3^{\mathrm{ab}}$ & $30.6^{\mathrm{a}}$ \\
\hline \multirow{3}{*}{ Susceptible } & Chunpoong & $26.3^{\mathrm{bc}}$ & $25.9^{\mathrm{c}}$ & $21.0^{\mathrm{cd}}$ \\
& HTIS1 & $26.1^{\mathrm{c}}$ & $26.6^{\mathrm{c}}$ & $21.1^{\mathrm{cd}}$ \\
\hline \multirow{2}{*}{ Control } & Jakyungjong & $28.8^{\mathrm{abc}}$ & $30.1^{\mathrm{abc}}$ & $26.3^{\mathrm{ab}}$ \\
\hline \multicolumn{2}{c}{ CV (\%) } & 8.0 & 13.6 & 15.8
\end{tabular}

HTIR, high temperature injury resistance; HTIS, high temperature injury susceptible; $\mathrm{CV}$, coefficient of variation.

${ }^{1)}$ With different letters are significantly different at the $1 \%$ level by the Duncan's test. mission increases by 5, 10, 20, and 30\%. Moreover, they showed that the decrease in chlorophyll is heightened at times approaching the hot season in August, caused by the destruction of chlorophylls in mesophyll cells of leaves exposed to intense light via photooxidation. Analyses of variance for seasonal chlorophyll content showed highly significant differences $(p=0.01)$ among ginseng lines; no prominent differences in chlorophyll content were observed between susceptible and resistant lines in June, but remarkable differences were detected in July and August. This suggests that ginseng lines resistant to leaf burning can be selected by assessing the chlorophyll content during the hot summer season of July and August.

Photosynthetic processes are the first to be damaged in plants growing at high temperatures with excess light, and photoinhibition of photosystem II occurs in tissues that are exposed to radiation beyond the levels usable for photosynthesis [11]. However, no significant differences in quantum yield were detected among these resistant and susceptible ginseng lines and Jakyungjong in June and July; however, the quantum yields of the resistant lines in August were 0.714, 0.693, 0.717, and 0.687 for Yunpoong, HTIR1, HTIR2, and HTIR3, respectively, while those of the susceptible lines were $0.647,0.631$, 0.603, and 0.619 for Chunpoong, HTIS1, HTIS2, and Jakyungjong, respectively, indicating that the quantum yield was significantly lower in the susceptible lines and Jakyungjong compared to resistant lines (Fig. 2). These values are likely related to inhibition of photosystem II activity, which reduces photosynthetic efficiency.

The maximum light interception rate $(\mathrm{Fm} / \mathrm{Fv})$ decreases in plants exposed to environmental stresses such as high temperatures, drought, and excess moisture, and is a nondestructive method for selecting plant lines resistant to leaf burning. The maximum $\mathrm{Fm} / \mathrm{Fv}$ is an important index of photoinhibition related to damage to reaction centers of photosystem II, decreasing the photochemical reaction rate and accelerating excitation energy to thermal energy. Photosynthetic dysfunction due to high temperatures is related to cellular environmental changes of $\mathrm{pH}$ and/or ionic composition affecting membrane permeability and leading to the inactivation of photosystem II [11].

No significant differences were observed in the maximum light interception rate among the resistant and susceptible lines and Jakyungjong in June and July 2008 in terms of quantum yield, indicating no significant heat damage during these months with few high-temperature days. Distinctive differences, however, were detected in 


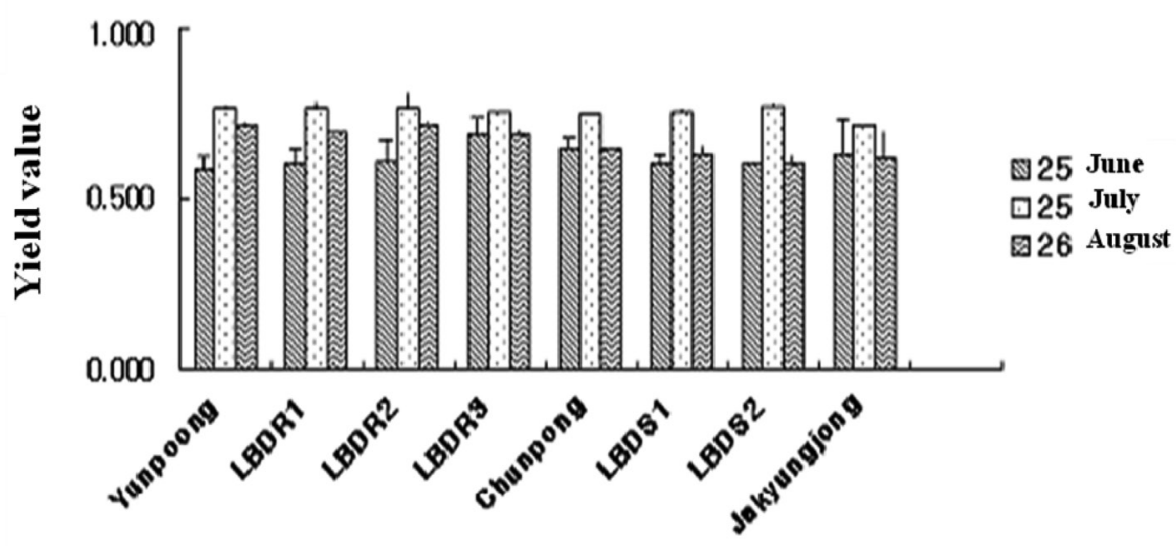

Fig. 2. Changes in quantum yield of 2-year-old resistant and susceptible ginseng lines in relation to high-temperature injury during the summer season. HTIR, high temperature injury resistance; HTIS, high temperature injury susceptible. Each bar represents means \pm SE $(n=3)$.

the maximum light interception rate in August, on days with high temperatures and excess light, among resistant and susceptible lines and Jakyungjong; the $\mathrm{Fm} / \mathrm{Fv}$ values were $0.848,0.794,0.805$, and 0.813 for the resistant lines Yunpoong, HTIR1, HTIR2, and HTIR3, respectively, but they were significantly lower at $0.678,0.642$, 0.717 , and 0.680 for the susceptible lines Chunpoong, HTIS1, HTIS2, and Jakyungjong, respectively (Fig. 3).

As shown in the quantum yield and maximum light interception rate data, the resistant ginseng lines selected in our study were resistant to photoinhibition, whereas the susceptible lines were sensitive. Activity of photosystem II also decreases in chili pepper grown at temperatures over $45^{\circ} \mathrm{C}$ (higher than the optimum growth temperature of $20^{\circ} \mathrm{C}$ ) [11], cucumber under low-temperature stress [12], and barley grown with salt $(\mathrm{NaCl})$ [13]. Our study gave similar results, whereby the maximum light interception was lower in susceptible lines, in which leaf burning inhibited the efficiency of photosystem II. In resistant lines, however, photosystem II efficiency was not as affected, making these lines more tolerant to hightemperature conditions.

\section{Affects on aerial part and belowground growth}

Leaf area and specific leaf weight are shown in Table 4. The leaf areas in the resistant lines were $100.3 \mathrm{~cm}^{2}$ for Yunpoong, $97.0 \mathrm{~cm}^{2}$ for HTIR1, $95.1 \mathrm{~cm}^{2}$ for HTIR2, and $63.1 \mathrm{~cm}^{2}$ for HTIR3, while in the susceptible lines, it was $53.5 \mathrm{~cm}^{2}$ for Chunpoong, $58.3 \mathrm{~cm}^{2}$ for HTIS1, 55.7 $\mathrm{cm}^{2}$ for HTIS2, and $77.5 \mathrm{~cm}^{2}$ for Jakyungjong. Highly significant differences $(p=0.01)$ were observed in leaf area among the ginseng lines examined, with a larger leaf area in leaf burning-resistant lines than in susceptible lines. The specific leaf weight was not significantly different between resistant and susceptible lines, with values for resistant lines of $3.3 \mathrm{mg} / \mathrm{cm}^{2}$ for Yunpoong, $3.4 \mathrm{mg} / \mathrm{cm}^{2}$ for HTIR1, $3.4 \mathrm{mg} / \mathrm{cm}^{2}$ for HTIR2, and $4.9 \mathrm{mg} /$ $\mathrm{cm}^{2}$ for HTIR3, and $3.7 \mathrm{mg} / \mathrm{cm}^{2}$ for Chunpoong, $3.4 \mathrm{mg} / \mathrm{cm}^{2}$

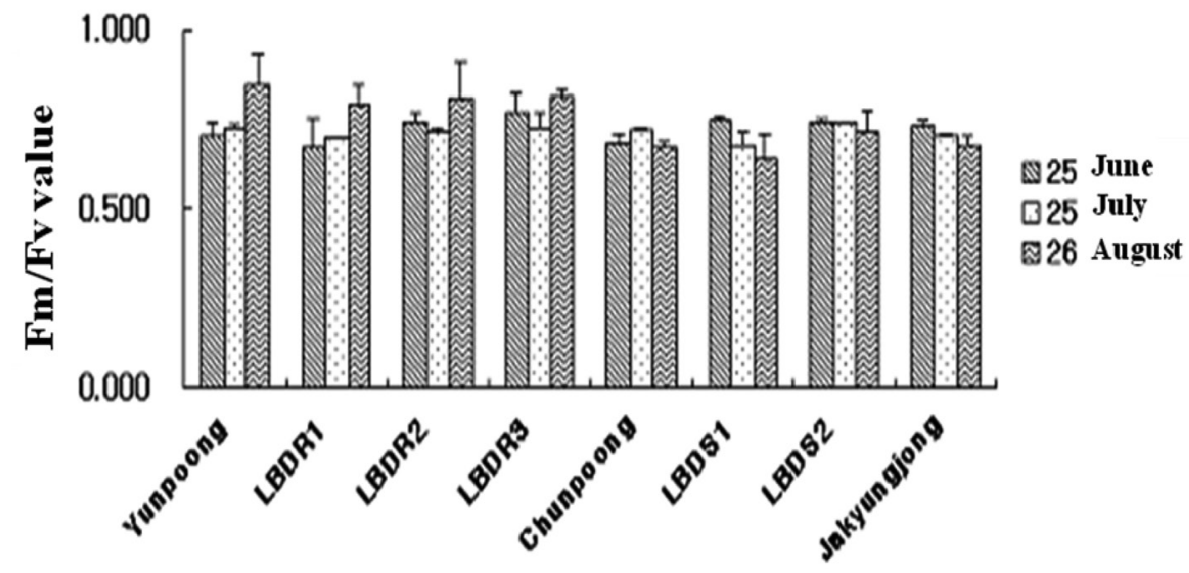

Fig. 3. Changes in fluorescence $(\mathrm{Fm} / \mathrm{Fv})$ in 2-year-old resistant and susceptible ginseng lines in response to high-temperature injury during the summer season. HTIR, high temperature injury resistance; HTIS, high temperature injury susceptible. Each bar represents means \pm SE $(n=3)$. 
Table 4. Characteristics of leaf areas and specific leaf weight in 2 -year-old ginseng lines resistant and susceptible to high temperature injury

\begin{tabular}{cccc}
\hline Reaction & Lines & $\begin{array}{c}\text { Leaf areas } \\
\left(\mathrm{cm}^{2} / \text { plant }\right)\end{array}$ & $\begin{array}{c}\text { Specific leaf eight } \\
\left(\mathrm{mg} / \mathrm{cm}^{2}\right)\end{array}$ \\
\hline \multirow{4}{*}{ Resistant } & Yunpoong & $100.3^{\mathrm{a}, 1)}$ & $3.3 \pm 0.3^{2)}$ \\
& HTIR1 & $97.0^{\mathrm{ab}}$ & $3.4 \pm 0.1$ \\
& HTIR2 & $95.1^{\mathrm{a}}$ & $3.4 \pm 0.1$ \\
& HTIR3 & $63.1^{\mathrm{bc}}$ & $4.9 \pm 0.7$ \\
\hline \multirow{3}{*}{ Susceptible } & Chunpoong & $53.5^{\mathrm{d}}$ & $3.7 \pm 0.2$ \\
& HTIS1 & $58.3^{\text {cd }}$ & $3.4 \pm 0.1$ \\
\hline \multirow{2}{*}{ Control } & HTIS2 & $55.7^{\mathrm{d}}$ & $3.1 \pm 0.3$ \\
\hline \multirow{2}{*}{ Jakyungjong } & $77.5^{\mathrm{bc}}$ & $3.3 \pm 0.2$ \\
\hline
\end{tabular}

HTIR, high temperature injury resistance; HTIS, high temperature injury susceptible; $\mathrm{CV}$, coefficient of variation.

${ }^{1)}$ With different letters are significantly different at the $1 \%$ level by the Duncan's test.

${ }^{2)}$ Values are presented as mean \pm SE.

for HTIS1, $3.1 \mathrm{mg} / \mathrm{cm}^{2}$ for HTIS2, and $3.3 \mathrm{mg} / \mathrm{cm}^{2}$ for Jakyungjong.

Lee et al. [8] reported that the leaf area and specific leaf weight are high in resistant ginseng lines selected from seedlings, but low in susceptible lines. In our study, the values were similar for leaf area, but different for specific leaf weight. This is probably because both resistant and susceptible plants had been grown under shading from April and so their leaf tissues were similarly thickened. Thus, the relationship of leaf burning phenomenon to specific leaf weight is not very clear in our study and further research should be conducted.

Belowground plant data are shown in Table 5. The root weights of 2-year-old ginseng plants were $5.4 \mathrm{~g}$, $5.7 \mathrm{~g}, 7.1 \mathrm{~g}$, and $5.7 \mathrm{~g}$ for the resistant lines Yunpoong, HTIR1, HTIR2, and HTIR3, respectively, and $3.5 \mathrm{~g}$, $5.1 \mathrm{~g}$, and $3.6 \mathrm{~g}$ for the susceptible lines Chunpoong, HTIS1, and HTIS2, respectively. The root diameters were $9.4 \mathrm{~mm}, 9.4 \mathrm{~mm}, 9.7 \mathrm{~mm}$, and $9.9 \mathrm{~mm}$ for Yunpoong, HTIR1, HTIR2, and HTIR3, respectively, and 7.9 $\mathrm{mm}, 8.6 \mathrm{~mm}$, and $8.3 \mathrm{~mm}$ for Chunpoong, HTIS1, and HTIS2, respectively. Root lengths of the resistant lines were $20.2 \mathrm{~cm}, 25.2 \mathrm{~cm}, 23.4 \mathrm{~cm}$, and $23.8 \mathrm{~cm}$ for Yunpoong, HTIR1, HTIR2, and HTIR3, respectively, and in the susceptible lines were $21.4 \mathrm{~cm}, 23.2 \mathrm{~cm}$, and $20.6 \mathrm{~cm}$ for Chunpoong, HTIS1, and HTIS2, respectively. For Jakyungjong, the root weight was $3.6 \mathrm{~g}$, root diameter was $8.9 \mathrm{~mm}$, and root length was $21.3 \mathrm{~cm}$. These results indicate that the root weight and diameter were larger in resistant than in susceptible lines, suggesting that dry matter accumulation in underground plant tissues may
Table 5. Characteristics of root weight, length and diameter in 2 -year-old ginseng lines resistant and susceptible to high temperature injury

\begin{tabular}{ccccc}
\hline Reaction & Lines & $\begin{array}{c}\text { Root weight } \\
(\mathrm{g})\end{array}$ & $\begin{array}{c}\text { Root length } \\
(\mathrm{cm})\end{array}$ & $\begin{array}{c}\text { Root diameter } \\
(\mathrm{mm})\end{array}$ \\
\hline \multirow{4}{*}{ Resistant } & Yunpoong & $5.4^{\mathrm{b}, 1)}$ & $21.2^{\mathrm{ab}}$ & $9.8^{\mathrm{a}}$ \\
& HTIR1 & $5.7^{\mathrm{b}}$ & $24.0^{\mathrm{a}}$ & $9.1^{\mathrm{abcd}}$ \\
& HTIR2 & $7.1^{\mathrm{a}}$ & $22.9^{\mathrm{ab}}$ & $9.7^{\mathrm{ab}}$ \\
& HTIR3 & $5.7^{\mathrm{b}}$ & $22.9^{\mathrm{ab}}$ & $9.2^{\mathrm{abc}}$ \\
\hline \multirow{3}{*}{ Susceptible } & Chunpoong & $3.5^{\mathrm{c}}$ & $20.1^{\mathrm{b}}$ & $7.9^{\mathrm{e}}$ \\
& HTIS1 & $5.1^{\mathrm{b}}$ & $21.5^{\mathrm{ab}}$ & $8.6^{\text {cde }}$ \\
\hline \multirow{2}{*}{ Control } & Jakyungjong & $5.1^{\mathrm{b}}$ & $21.3^{\mathrm{ab}}$ & $8.9^{\mathrm{bcd}}$ \\
\hline \multicolumn{2}{c}{ CV (\%) } & 22.6 & 7.6 & 7.5 \\
\hline
\end{tabular}

HTIR, high temperature injury resistance; HTIS, high temperature injury susceptible; $\mathrm{CV}$, coefficient of variation.

${ }^{1)}$ With different letters are significantly different at the $1 \%$ level by the Duncan's test.

be retarded in susceptible lines because of early defoliation caused by leaf burning, while normal dry matter accumulation occurs in resistant lines that are foliated without leaf burning, at least until harvest in September. The reduced belowground growth in 2-year-old ginseng will adversely affect the belowground growth of 3-yearold, and consequently 6-year-old, quality of red ginseng.

No significant differences were found in root length between resistant and susceptible lines. Lee et al. [4] reported that the leaf burning phenomenon differed depending on the root length of seedlings at the time of transplanting: $12 \%$ reduction for roots more than $10 \mathrm{~cm}$ long and $35.2 \%$ for roots of $8 \mathrm{~cm}$. However, the leaf burning phenomenon of susceptible lines was $35.2 \%$ on average (Table 2), even though roots of seedlings were $>10 \mathrm{~cm}$ long in our study. This suggests an influence of seedling root length on the development of leaf burning, whereby early root growth and water absorption during the drought season may be beneficial to ginseng plants with longer roots. The fact that leaf burning is not totally controlled by transplanting first-grade ginseng seedlings also supports this hypothesis. Further work should be done on the relationship of seedling root length and weight to leaf burning phenomenon.

Considering the results from our study, the resistant ginseng lines were not affected as much by high temperatures and excess light, with little chlorophyll destruction through photooxidation and low photoinhibition that maintained photosystem II activity. More studies on leaf tissues in the selected ginseng lines will be conducted, so that the resistant ginseng lines can be used as midparents (genetic resources) for leaf burning resistance 
breeding. Also, studies on ginseng yield, red ginseng quality, components analysis, photosynthesis, and field experimentation will be conducted to verify variety potentials, elucidate leaf burning effects, and expand areas for ginseng cultivation.

\section{REFERENCES}

1. Yang DC, Yoo HS, Yoon JJ. Investigation on the photooxidation of pigment in leaf-burning disease of Panax ginseng. I. Phenomenological observation and analysis on the chlorophyll bleaching phenomenon. Korean J Ginseng Sci 1987;11:91-100.

2. Yang DC, Yoo HS, Yoon JJ. Investigation on the photooxidation of pigment in leaf-burning disease of Panax ginseng. II. Investigation and analysis of physiological reaction mechanisms on the chlorophyll bleaching phenomenon. Korean J Ginseng Sci 1987;11:101-110.

3. Mok SK, Ban YS, Cheon SK, Lee TS, Lee SS, Lee JJ, Park DW, Lee JK, Park SH. Study of cultivation technology for cost-saving in ginseng. Daejeon: Korean Ginseng \& Tobacco Research Institute, Research Report of Ginseng (Part of Ginseng Cultivation) Press, 1994.

4. Lee TS, Mok SK, Jin JE, Yoon JH, Cheon SK, Min BS. Study of improved cultivation methods for white ginseng quality. Daejeon: Korean Ginseng \& Tobacco Research Institute, Research Report of Ginseng (Part of Ginseng Cultivation) Press, 2001

5. Lee MG, Lee SS, Kwon US, Lee JH, Kang JY, Choi KT, Chung YY, Park SO, Nam IY. Study of new cultivar breeding of ginseng. Daejeon: Korean Ginseng \& Tobacco Research Institute, Research Report of Ginseng (Part of Gingeng Cultivation) Press, 1999.
6. Lee SS, Ahn IO, Lee JH, Park DW. Study of disease resistance and high quality in ginseng breeding. Daejeon: Bio-resources Center, KT\&G Central Research Institute, Research Report of Ginseng (Part of Ginseng Breeding) Press, 2003.

7. Lee SS, Ahn IO, Lee JH, Park DW. Study of disease resistance and high quality in ginseng breeding. Daejeon: Bio-resources Center, KT\&G Central Research Institute, Research Report of Ginseng (Part of Ginseng Breeding) Press, 2004.

8. Lee SS, Ahn IO, Lee JH, Lee JS, Park DW. New cultivar development for high quality and disease resistance in ginseng. Daejeon: Bio-resources Center, KT\&G Central Research Institute, Research Report of Ginseng (Part of Gingseng Breeding) Press, 2007.

9. Korea Meteorological Administration. Monthly weather report. Available from: http://kma.go.kr/weather/ovservation/past_cal.jsp.

10. Lee JC, Cheon SK, Kim YT, Kim SD, Ahn SB. Studies on the optimum light intensity for growth of Panax ginseng. II. Study on difference of optimum light intensity for the growth of ginseng plant according to root age. Korean $\mathrm{J}$ Ginseng Sci 1982;6:149-153.

11. Lee HY, Nam JW, Hong YN. Photoinhibition of PSII in leaves of pepper under various light intensities and temperatures. J Plant Biol 1995;38:373-380.

12. Chun HS, Moon BY, Lee CH, Chung IK, Park IH, Lee CB. Light-dependent chilling injury on the photosynthetic activities of cucumber cotyledons. Korean J Bot 1993;36:133-140.

13. Chung HW, Lim YJ, Park KE, Park SY. The effect of $\mathrm{NaCl}$ on chl fluorescence of barley (Hordeum vulgare L.) leaves. J Environ Sci 2004;13:1015-1021. 